\title{
Detecção de estruturas acumuladoras de água subterrânea no substrato cristalino de Campina Grande, PB
}

\author{
Juliana Targino Batista', José Agnelo Soares ${ }^{1}$, Nigério dos Santos Sousa', 'Universidade Federal de Campina Grande
}

Copyright 2018, SBGf - Sociedade Brasileira de Geofísica

Este texto foi preparado para a apresentação no VIII Simpósio Brasileiro de Geofísica, Salinópolis, 18 a 20 de setembro de 2018 . Seu conteúdo foi revisado pelo Comitê Salinópolis, 18 a 20 de setembro de 2018. Seu conteúdo foi revisado pelo Comite
Técnico do VIII SimBGt, mas não necessariamente representa a opinião da SBGf ou de seus associados. É proibida a reprodução total ou parcial deste material para propósitos comerciais sem prévia autorização da SBGf.

\section{Resumo}

O presente trabalho apresenta o resultado da aplicação do método geofísico de eletrorresistividade no reconhecimento de aspectos de natureza hidrogeológica na área conhecida como Sítio Catarina, no município de Campina Grande, Paraíba. Este estudo teve como objetivo a caracterização geoelétrica do substrato rochoso dessa região, a fim de detectar anomalias resistivas e/ou condutivas correlacionáveis com a presença de estruturas (falhas e fraturas) passíveis à acumulação e circulação de água, favorável à locação de poços tubulares para captação de água subterrânea naquela área. Foram identificados nos modelos geoelétricos dos dois perfis realizados a presença de três alvos hidrogeológicos: o aluvião, as zonas fraturadas condutivas e os sistemas complexos formados pelo aluvião - manto de intemperismo - zonas fraturadas, sendo este último o que apresenta o maior potencial hidrogeológico.

\section{Introdução}

O município de Campina Grande, Paraíba, encontra-se inserido no denominado Polígono das Secas, região cujo clima dominante é o semi-árido, apresentando baixa pluviosidade média anual, com elevados índices de evapotranspiração ao longo de todo o ano, solos pouco espessos, com rede de drenagem constituída por cursos d'água intermitentes sazonais de pequena energia. Combinado a esses fatores, cerca de $70 \%$ do substrato dessa região é composto por rochas ígneas e metamórficas. Dessa forma, o potencial hídrico subterrâneo do município está associado à presença de descontinuidades aproximadamente planares existentes no substrato, onde a quantidade e até mesmo a existência de água subterrânea através da rocha de baixa porosidade primária vai depender, principalmente, da abertura e conectividade das fraturas pré-existentes. Diante desse contexto, a extração de água subterrânea nesta região é majoritariamente realizada em aquíferos fissurais no embasamento cristalino, resultando em poços, em geral, de baixa produtividade.

Tradicionalmente a metodologia utilizada na prospecção hidrogeológica em terrenos cristalinos no Nordeste do Brasil é baseada na utilização de critérios geológicos, através da análise de fotografias aéreas e da geologia de superfície, constituindo-se numa técnica relativamente rápida e que não exige muitos recursos para a sua execução. Entretanto, o índice de insucesso associado às locações de poços utilizando essa metodologia é bastante elevado, de modo que a investigação das zonas fraturadas na rocha sã representa um desafio constante para os hidrogeólogos. Diante do contexto apresentado, o presente trabalho busca integrar os dados geológicos e geofísicos para a caracterização das estruturas acumuladoras de água subterrânea, de forma a reduzir o índice de incerteza associado às locações de poços nestes terrenos.

Geologicamente a área investigada no presente trabalho, contida na folha Campina Grande, pertence ao terreno Alto Pajeú (TAP), inserido no domínio da Zona Transversal da Província da Borborema (Figura 1). O mapeamento sistemático realizado por Rodrigues (2008) caracterizou nessa área uma série de zonas de cisalhamentos verticais de direção NW destrais e de direção NE sinistrais que formam um sistema conjugado situado no segmento oriental do Lineamento Patos, o qual é denominado "Sistema de Cisalhamento Campina Grande". A área de estudo investigada, conhecida como Sítio Catarina, situa-se a NW da cidade de Campina Grande e compreende um vale com orientação NW-SE, comprimento de aproximadamente $8 \mathrm{Km}$, encaixado na zona de cizalhamento destral de Puxinanã (Figura 2). Apresenta rochas correlatas aos litotipos associados às unidades neoproterozóicas Cariris Velhos e São Caetano. $\mathrm{Na}$ unidade Cariris Velho ocorre a predominância de rochas como ortognaisses, migmatitos e muscovita-biotita gnaisses. Já no Complexo São Caetano predominam rochas calciossilicáticas, xistos, granitóides e milonitos variados (Rodrigues et al., 2011).

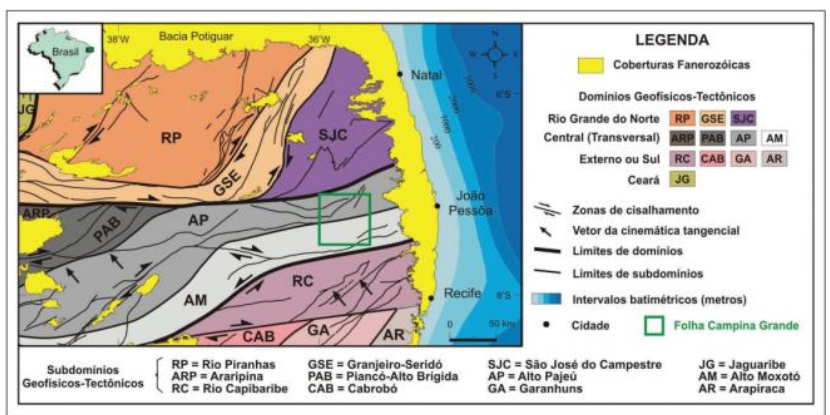

Figura 1 - Divisão da porção setentrional da Província Borborema em domínios/subdomínios geofísicostectônicos (Rodrigues et al., 2011).

Neste estudo foram realizados dois perfis geoelétricos de direção aproximada NE-SW, cruzando transversalmente o vale de orientação NW-SE, localizados próximos de um cotovelo de drenagem. $\mathrm{Na}$ área investigada predomina um relevo ondulado com acentuados declives para as direções norte e sul. No riacho, em toda a sua extensão, 
e principalmente no local onde ocorre a mudança de direção, tem-se a acumulação de uma cobertura aluvionar-coluvionar arenosa, onde na margem sul do riacho o aluvião possui uma granulometria de areia grossa. Já na margem norte verifica-se que a granulometria dos sedimentos é dominada por areia fina a média. Verifica-se ainda a presença de afloramentos em seu leito que seriam indicativos que o substrato rochoso é composto por augen granito-gnaisse, com foliação verticalizada de orientação E-W. As drenagens subsidiárias orientam-se ao longo da foliação e dos lineamentos de direção N-S. Nesta área é possível identificar, segundo Souza Filho et al. (2016), três famílias de fraturas: Fr.1 - Tração (350/86-90) apresentando moderada a larga abertura entre paredes; Fr.2 - Cisalhantes (180/60; 355/54-70) de estreita abertura entre paredes e Fr.3 (059/60) de estreita abertura entre paredes.

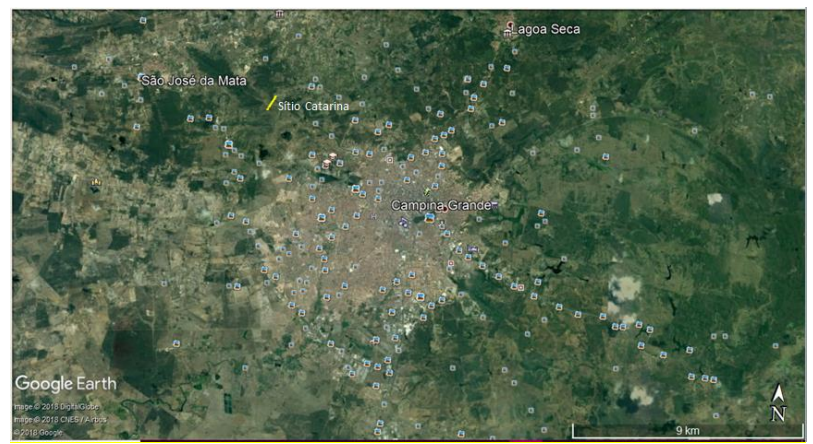

Figura 2 - Localização da área de estudo - Sítio Catarina - no município de Campina Grande, Paraíba.

O vale onde foram realizados os perfis geoelétricos apresenta a configuração de um modelo riacho-fenda clássico, desenvolvido por Siqueira (1963). Este modelo tem como base a associação da hidrografia com a geologia, partindo do princípio que os trechos retilíneos de riachos coincidem com zonas fortemente fraturadas, permitindo que as fraturas sejam periodicamente recarregadas pela drenagem (Figura 3 ). Essa morfologia é de fácil observação, através dos cotovelos e feições retilíneas dos trechos de rios e riachos, paralelos às direções preferenciais de fraturas no cristalino aflorante (Coriolano, 2002).

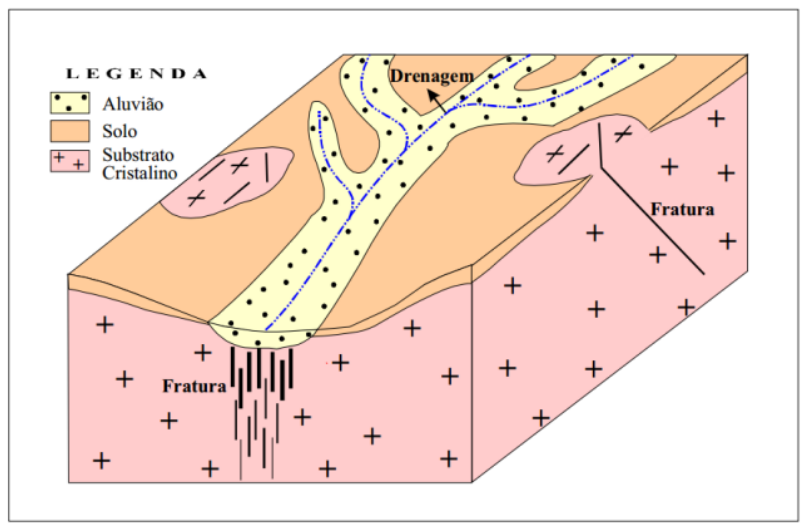

Figura 3 - Modelo riacho-fenda. (Coriolano, 2002).

\section{Metodologia}

Para a caracterização geofísica realizada no Sítio Catarina foi empregado o método geoelétrico de eletrorresistividade. Esse método é baseado na determinação da resistividade elétrica dos materiais a partir das medições do potencial elétrico na superfície, tornando possível determinar, no subsolo, a existência de corpos minerais e reconhecer estruturas geológicas, devido a existência dos contrastes dos valores de resistividade elétrica mensurada, em relação aos materiais geológicos que formam o substrato (Telford et al., 1990).

Dois procedimentos foram empregados nos levantamentos de resistividade, simultaneamente: a Sondagem Elétrica Vertical (SEV) e o Caminhamento Elétrico (CE), combinadas com a configuração de eletrodos Schlumberger ao longo das linhas investigadas. A SEV permite a investigação das variações verticais de resistividade aparente de diferentes camadas horizontais ou sub-horizontais do subsolo com a profundidade efetuada em um ponto fixo na superfície do terreno (centro da SEV). Enquanto que $\mathrm{O} C E$ investiga as variações laterais na resistividade do terreno em uma ou mais profundidades determinadas, através do deslocamento do conjunto de eletrodos com espaçamento fixo, apresentando uma boa resposta na determinação de descontinuidades laterais dos materiais geológicos em subsuperfície, tais como diques, contatos geológicos, fraturamentos e/ou falhamentos (Braga, 2016).

A forma geral da configuração de eletrodos usadas em medições de eletrorresistividade constitui de quatro eletrodos cravados na superfície do terreno. Um par de eletrodos $(A B)$ é responsável por introduzir corrente elétrica no subsolo, enquanto que o outro par de eletrodos (MN) mede a diferença de potencial resultante. O arranjo Schlumberger, utilizado para a realização deste levantamento, é caracterizado por manter os eletrodos $M$ e $\mathrm{N}$ fixos durante o desenvolvimento da SEV, enquanto que os eletrodos A e B apresentam uma separação crescente em relação ao centro do arranjo, mantendo sempre a relação $\mathrm{MN} \leq \mathrm{AB} / 5$ durante todo $\mathrm{O}$ levantamento de campo (Figura 4).

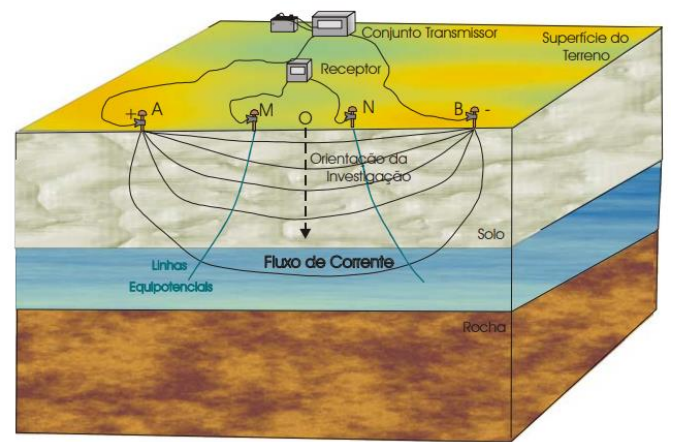

Figura 4 - Representação esquemática da configuração de arranjo Schlumberger (Oliva, 2002). 
Para a analise da área estudada foram realizados dois perfis geoelétricos. O Perfil 1 apresenta extensão máxima de 370 metros sendo composto por quinze SEVs espaçadas umas das outras por 20 metros. O Perfil 2 apresenta extensão máxima de 300 metros, sendo composto por nove SEVs espaçadas umas das outras por 25 metros. Em ambos os perfis, cada SEV possui afastamento fixo de 2 metros entre os eletrodos de medição de potencial, abertura máxima de 100 metros e mínima de 20 metros entre os eletrodos de injeção de corrente. O espaçamento entre os eletrodos de corrente foi de 10 metros. O que variou de um perfil para o outro foi apenas o afastamento entre SEVs que no Perfil 1 foi de 20 metros, já no Perfil 2 foi de 25 metros, por uma questão de praticidade na mudança do arranjo durante a aquisição dos dados ao longo da linha investigada.

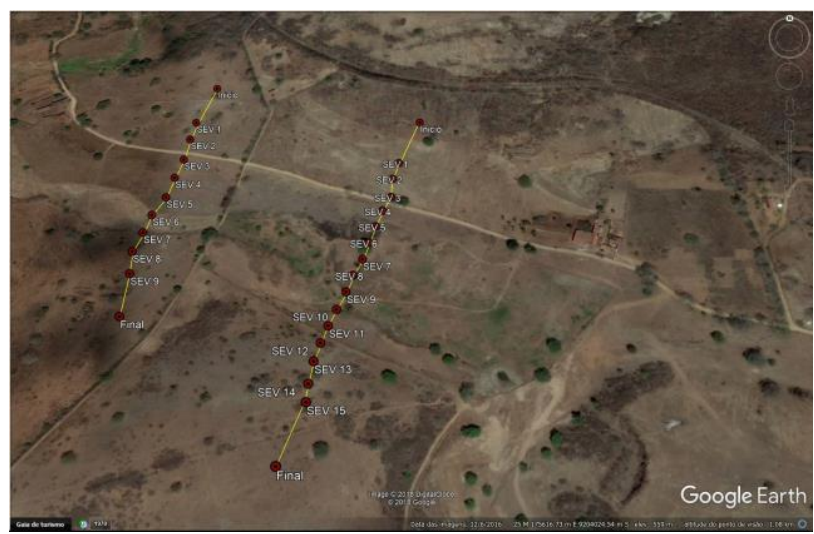

Figura 5 - Imagem de satélite com a representação da distribuição dos perfis na superfície do terreno no Sítio Catarina.

Os dados obtidos para os dois perfis geoelétricos do Sítio Catarina foram processados utilizando o software RES2DINV v. 3.52. Este software realiza inversões bidimensionais (2D) dos dados de resistividade obtidos em campo. O modelo adotado pelo RES2DINV consiste em dividir a subsuperfície em uma quantidade finita de blocos, sendo aplicada uma inversão baseada no método dos mínimos quadrados, para atribuir o valor de resistividade aparente a cada bloco, em conformidade com os valores obtidos em campo (Loke \& Barker, 1996). Após o processo de inversão foram incluídos os valores de topografia, gerando os modelos geoelétricos (2D) correspondentes aos dois perfis, onde os mesmos são apresentados como pseudo-seções caracterizadas pela representação gráfica da variação da resistividade em função da distância e profundidade (neste caso, a altitude do terreno).

\section{Resultados e Discussões}

A inversão conjunta das SEVs do Perfil 1 resultou na seção geoelétrica mostrada na Figura 6, apresentando uma profundidade de investigação de aproximadamente 20 metros, onde foram identificados dois alvos hidrogeológicos. É importante ressaltar que as seções geradas no RES2DINV têm início e final nos centros da primeira e da ultima SEV, respectivamente, portanto, a 50 metros das extremidades da linha investigada, isto porque foi utilizado um $A B$ máximo de 100 metros. Nesta seção a planície aluvionar ocorre entre as SEVs 4 e 9, se estendendo desde a superfície até aproximadamente 10 metros de profundidade, apresentando valores de resistividade aparente variando entre 2.3 e 20 ohm.m. Entre as SEVs 10 e 13 verifica-se a presença do leito atual do riacho, com cobertura sedimentar de aproximadamente 10 metros de profundidade e valores de resistividade também variando entre 2.3 e 20 ohm.m. Abaixo dessa cobertura sedimentar se encontra 0 embasamento alterado de rochas metamórficas, apresentando valores de resistividades medianos, entre 80 e 480 ohm.m. Abaixo de 18 metros de profundidade predominam rochas de alta resistividade elétrica (> 500 ohm.m), indicativo da rocha sã e não fraturada. Entre as SEVs 3 e 9 verifica-se a presença de fraturas condutivas verticalizadas e/ou subverticalizadas representadas na seção pelos traços em coloração vermelha, sendo este intervalo o de maior potencial hídrico. Verifica-se ainda entre as SEVs 9 e 12 a presença de outro sistema de fraturas verticalizadas e/ou subverticalizadas condutivas que corresponde a um intervalo com potencial hidrogeológico secundário. Nas SEVs 1 e 2 as rochas do embasamento cristalino, de muito baixa porosidade, afloram na superfície do terreno, como observado durante o levantamento de campo.

A inversão conjunta das SEVs do Perfil 2 resultou em uma seção geoelétrica (Figura 7) apresentando uma profundidade de investigação de cerca de 20 metros, a qual exibe a ocorrência de uma cobertura sedimentar condutiva pouco espessa (aproximadamente 8 metros) entre a SEV 1 e a SEV 3 , apresentando valores de resistividade de até 35 ohm.m. Abaixo dessa cobertura sedimentar se encontra o embasamento de rochas metamórficas alteradas, apresentando valores de resistividades medianos, variando entre 60 e 600 ohm.m. Abaixo de 18 metros de profundidade predominam rochas de alta resistividade elétrica (> 1000 ohm.m), indicativo da rocha sã e não fraturada. Nas posições correspondentes às SEVs 3 e 6 foi possível identificar a presença de fraturas condutivas verticalizadas e subverticalizadas representadas na seção pelos traços em coloração vermelha, sendo este trecho o de maior potencial hidrogeológico. A geometria observada nesta seção geoelétrica é compatível com 0 modelo hidrogeológico do tipo riacho-fenda. Entre as SEVs 7 e 8 predomina a ocorrência de uma zona de rocha alterada, com valores medianos de resistividade. Entre as SEVs 8 e 9 as rochas do embasamento cristalino, de muito baixa porosidade, afloram na superfície do terreno, apresentado valores de resistividade acima de 1000 ohm.m. Entre as SEVs 4 e 6 , para profundidades de até 6 metros, observa-se uma zona de alta resistividade que é interpretada como correspondendo a blocos de rocha sã rolados sobre o leito do riacho. 


\section{Conclusões}

A avaliação do sistema aquífero fissural estudado é uma tarefa complexa, entretanto, em conformidade com os objetivos propostos para o estudo, pode-se considerar que os resultados obtidos evidenciam a potencialidade de aplicação do método da eletrorresistividade como uma eficiente ferramenta de auxílio na caracterização hidrogeológica de potenciais aquíferos fissurais da área estudada. A interpretação integrada dos dados estruturais e geofísicos no Sítio Catarina evidenciou a existência de estruturas promissoras ao acúmulo de água no cristalino, compatível com o modelo do tipo riachofenda, desenvolvido por Siqueira (1963).

As pseudo-seções de resistividade geradas para os Perfis 1 e 2 possibilitaram a delimitação da zona fraturada e sua direção, fornecendo uma boa indicação da topografia do topo do cristalino sobre o qual está acumulada a cobertura sedimentar (aluvionar-coluvionar). A aplicação do método de eletrorresistividade ofereceu uma excelente resposta com relação à localização da zona fraturada e determinação do seu eixo de prolongamento e profundidade relativa. Proporcionou ainda a delimitação dos locais da calha do riacho que apresentam maior espessura de aluvião e/ou regolito. O controle estrutural por fraturas é identificado nos modelos geoelétricos 2D através da presença de anomalias condutivas, relativamente profundas, que não apresentam necessariamente continuidade ou propagação para a superfície, decorrentes do grau de intemperismo da rocha ou sedimentos (aluvião ou regolito) armazenando água subterrânea ao longo da rede de fraturas.

\section{Agradecimentos}

Os autores agradecem a colaboração Lucas Emanuel Batista de Oliveira, Paula Rayane Lopes de Andrade, Wesley Mendonça e Túlio César Pereira Aquino que ajudaram na aquisição de dados de campo.

\section{Referências}

Braga, A.C.O., 2016. Métodos Geoelétricos em Hidrogeologia. Editora Oficina de Textos, 159 pp.

Coriolano, A. C. F., 2002. Reavaliação de Critérios Estruturais na Hidrogeologia de Terrenos Cristalinos, com Ênfase na Neotectônica e Sensoriamento Remoto. Tese (Doutorado) - Centro de Ciências Exatas e da Terra. Universidade Federal do Rio Grande do Norte, Natal, 199 p.

Loke M. H.; Barker R. D., 1996. Rapid least-squares inversion of apparent resistivity pseudosections by a quasi-Newton method. Geophysical Prospecting, v. 44, p.131-152.
Oliva, A., 2002. Estudo Hidrogeológico da Formação Rio Claro no Município de Rio Claro -SP. Dissertação de Mestrado - Instituto de Geociências e Ciências Exatas Unesp- Rio Claro, 71 pp.

Rodrigues, S. W. O., 2008. Evolução Estrutural Brasiliana da Província da Borborema na Região de Campina Grande (PB). Tese de Doutorado. Programa de Pós-Graduação em Geoquímica de Geotectônica. Universidade Federal de São Paulo. Instituto de Geociências. 227 p.

Rodrigues, S. W. O., Medeiros, V. C., Marinho, M. S., Oliveira, R. G., 2011. Geologia e recursos minerais da Folha Campina Grande (SB.25-Y-C-I). Brasília: CPRM/SBG, 2011. 101p. Programa Geologia do Brasil.

Turner, F. J. \& Werhoogen, J., 1960. Igneous and metamorphic petrology. 2nd ed., McGraw Hill, New York, USA.

Siqueira, L., 1963. Contribuição da geologia à pesquisa de água subterrânea no cristalino. SUDENE, Relatório Interno, Recife-PE. 51p.

Souza Filho, O. A.; Domingos, N. R. R.; Oliveira, R. G.; Galvão, M. J. T. G; Lages, G. A., 2016. Levantamentos eletromagnéticos para água subterrânea em Campina Grande, Paraíba, Brasil. Anais do VII Simpósio Brasileiro de Geofísica, Ouro Preto.

Telford, W. M.; Geldart, L. P.; Sheriff, R. E.; Keys, D. A., 1990. Applied geophysics. Cambridge University Press, $866 \mathrm{p}$. 


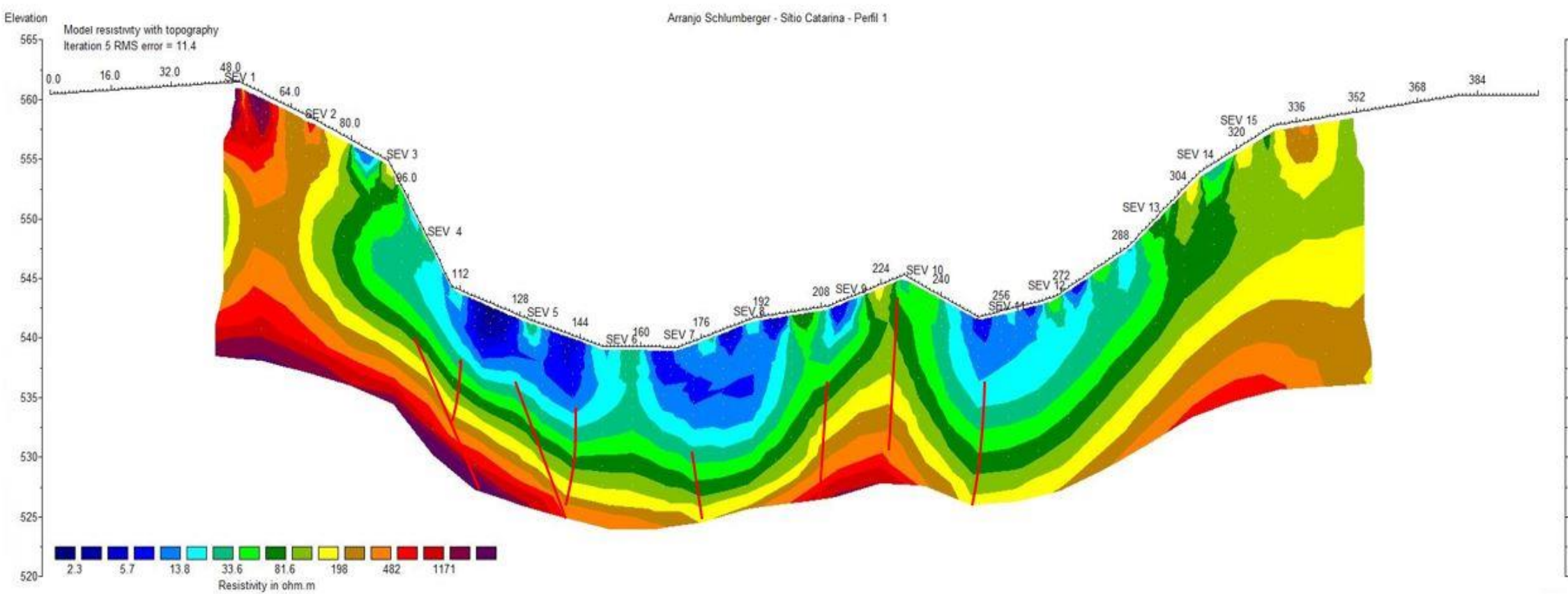

Figura 6 - Seção geoelétrica do Perfil 1. 
Model resistivity with topography

Elevation Iteration 6 RMS error $=24.9$

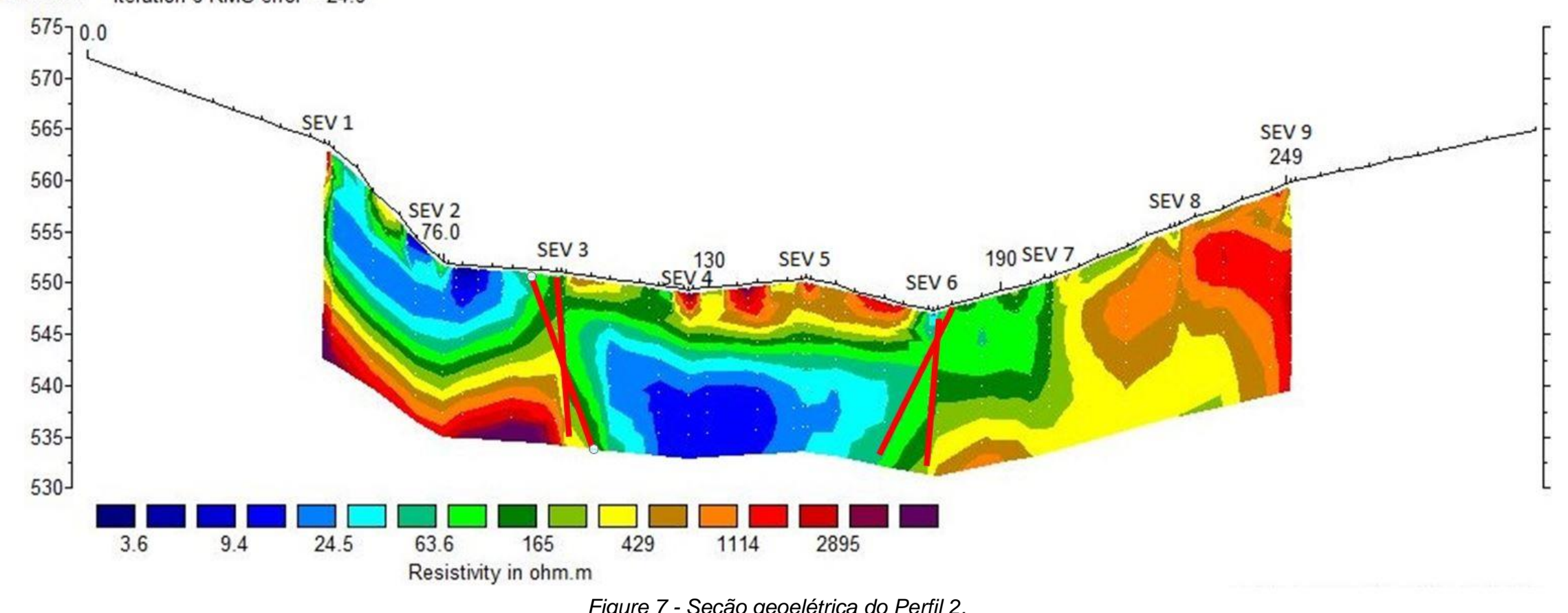

Figure 7 - Seção geoelétrica do Perfil 2. 